\title{
FARELO DE ALGODÃO EM RAÇÕES PARA SUÍNOS NAS FASES DE CRESCIMENTO E TERMINAÇÃO
}

\author{
COTTONSEED MEAL IN DIETS FOR GROWING AND FINISHING PIGS
}

\author{
Mello, G. ${ }^{1}$, Laurentiz, A.C. ${ }^{1}$, Filardi, R.S. ${ }^{1 *}$, Bergamaschine, A.F. ${ }^{1}$, Okuda, H.T. ${ }^{1}$, Lima, M.M. ${ }^{1}$ \\ e Junqueira, O.M. ${ }^{2}$
}

${ }^{1}$ Faculdade de Engenharia. UNESP. Universidade Estadual Paulista. Campus de llha Solteira. Departamento de Biologia e Zootecnia. Ilha Solteira, SP. Brasil. *rosefilardi@bio.feis.unesp.br

${ }^{2}$ Faculdade de Ciência Agrárias e Veterinárias. UNESP. Universidade Estadual Paulista. Campus de Jaboticabal, Departamento de Zootecnia. Jaboticabal. Brasil.

\section{PalaVRas chaVe adicionais}

Alimento alternativo. Dejeto suíno. Análise econômica.

\section{RESUMO}

Quarenta e oito suínos, de 63 dias e peso de $23,40 \pm 1,3 \mathrm{~kg}$, foram distribuídos em um delineamento experimental em blocos casualizados, com três tratamentos $(0 \%, 10 \%$ e $20 \%$ de inclusão de farelo de algodão -FA- nas rações) e oito repetições compostas de dois animais (um macho castrado e uma fêmea). Os blocos foram utilizados para controlar variações no peso corporal inicial. O período experimental compreendeu a fase de crescimento ( 63 a 106 dias) e crescimentoterminação (63 a 147 dias de idade). Em cada uma das fases as rações foram isonutritivas, variando, entretanto, os níveis de fibra bruta. Os níveis de FA não afetaram o desempenho dos animais. A avaliação qualitativa dos dejetos indicou que o FA determinou redução nos teores de fósforo e nitrogênio, mas apenas na fase de crescimento. $\mathrm{Na}$ fase de terminação o aumento na inclusão de FA promoveu aumento no teor de matéria seca dos dejetos. O FA pode ser utilizado em até $20 \%$ nas rações para suínos na fase de crescimento e terminação, porém a necessidade de inclusão de L-lisina e óleo de soja determina aumento no custo/ $\mathrm{kg}$ de suíno produzido.

\section{SUMMARY}

Forty-eight pigs with 63 day olds and average weight of $23.40 \pm 1.3 \mathrm{~kg}$, were allotted in a randomized block design with three treatments

\section{AdDitional KeYWORDS}

Alternative feed. Swine manure. Economic analysis.

$(0 \%, 10 \%$ and $20 \%$ of cottonseed meal (FA) in diets) and eight replicates with two pigs (one barrow and one gilt). The blocks were used to control changes in initial body weight. Experimental period was the growth phase (63 to 106 days old) and growing-finishing (63 to 147 days old). In each phase the diets were isonutritives, varying however the levels of crude fiber. The levels of cottonseed meal (FA) did not affect $(p>0.05)$ the performance of animals during the growth phase or during the total period of evaluation (growingfinishing). The qualitative parameters of manure indicated that the FA determined decrease in the nitrogen and phosphorus content, but only in the growth phase. In the finishing phase the increase in the FA inclusion promoted an increase in dry matter content. Although FA can be used in up to $20 \%$ in diets for pigs in the growing and finishing phase, it is necessary to include L-lysine and soybean oil which causes an increase in cost per $\mathrm{kg}$ produced pig.

\section{INTRODUÇÃO}

A nutrição animal possui papel relevante nos sistemas de produção de suínos, pois visa melhorar o aproveitamento dos alimentos, gerando menor excreção de nutrientes e possibilitar maior lucro com a atividade 
(Marcato e Lima, 2005). As crises nos últimos anos e questões referentes à poluição ambiental têm levando suinocultores a procurarem alternativas nutricionais para diminuição dos custos com a criação. Uma das formas empregadas é a substituição de ingredientes tradicionais das rações, como o milho e farelo de soja, por alimentos alternativos como o farelo de algodão (FA), subproduto resultante da moagem do caroço de algodão no processo industrial para a extração do óleo.

O FA é o terceiro dos farelos protéicos mais produzidos no mundo, sendo a maior parte utilizada na alimentação de ruminantes. Embora seu emprego em rações para suínos seja limitado pelo conteúdo de gossipol e baixa digestibilidade de aminoácidos essenciais, além da grande variação na qualidade da proteína (Prawirodigdo et al., 1997), o FA pode ser uma alternativa como fonte de proteína nas rações para suínos (Chiba, 2001).

Os tratamentos térmicos aplicados ao FA favorecem a formação de complexos inertes e indigestíveis entre o gossipol e a lisina. Na forma complexada o gossipol não é tóxico aos animais, pois o complexo não é absorvido no trato gastrointestinal, entretanto ocorre diminuição na disponibilidade da lisina e na digestibilidade da proteína (Ezekiel, 2002). Com relação ao gossipol livre, tóxico para suínos e aves, Chiba (2001) preconiza que a toxicidade pode ser prevenida pela adição de sais de ferro à dieta, como o sulfato ferroso, de forma que para níveis superiores a 100 ppm de gossipol livre a relação entre ferro e gossipol livre deve ser de 1:1 em peso.

O FA comercializado possui de 36 a $41 \%$ de PB, variação decorrente da forma pela qual o óleo é extraído, o que também determina proporções diversas de semente, casca, óleo e línter (Tanksley Jr., 1990). Além disso, o FA apresenta baixo teor de energia (2379 kcal de ED/kg) quando comparado ao farelo de soja (Rostagno et al., 2005), isso em função do seu elevado teor de fibra, pois de acordo com o NRC (1998), possui 11 a $13 \%$ de FB e $28,4 \%$ de FDN. Segundo Decamp et al. (2001), a inclusão de ingredientes fibrosos nas dietas de suínos pode melhorar algumas características dos dejetos, como a presença de nitrogênio nas fezes e a emissão de odores.

Em dietas para suínos nas fases de crescimento e terminação, o FA como única fonte de proteína suplementar determina redução no desempenho, isso quando comparado com dietas cuja fonte protéica é o farelo de soja (Chiba, 2001). Entretanto, alguns estudos (Balogun et al., 1990 e Paiano et al., 2003, 2006) indicam que quando as dietas são formuladas com níveis adequados de proteína e outros nutrientes essenciais, o FA pode ser incluído em até $10 \%$ sem afetar o desempenho de suínos nas fases de crescimento e terminação.

Objetivou-se com o estudo avaliar os efeitos da inclusão de FA sobre o desempenho de suínos na fase de crescimentoterminação, aspectos qualitativos dos dejetos e viabilidade econômica.

\section{MATERIALE MÉTODOS}

O experimento foi conduzido nas dependências do Setor de Suinocultura da Fazenda de Ensino, Pesquisa e Extensão da Faculdade de Engenharia, Universidade Estadual Paulista, Campus de Ilha Solteira, localizado na região extremo Noroeste do estado de São Paulo, Brasil. Durante o período experimental as temperaturas médias, mínima e máxima registradas no interior do galpão, foram $24 \pm 2,7^{\circ} \mathrm{Ce} 32 \pm 3,1^{\circ} \mathrm{C}$, respectivamente.

Foram utilizados 48 suínos, machos castrados e fêmeas, com idade média de 63 dias e peso médio de $23,4 \pm 1,3 \mathrm{~kg}$. Os animais foram alojados em baias de alvenaria (dois animais por baia) com piso compacto e equipadas com bebedouro tipo vasos comunicantes e comedouro tipo cocho de concreto.

O delineamento experimental utilizado foi em blocos inteiramente casualizados, 
com três tratamentos e oito repetições de dois animais (um macho e uma fêmea). Os tratamentos consistiram de três níveis de inclusão de FA $(0,10$ e 20\%) nas rações experimentais. Os blocos foram utilizados para controlar variações no peso corporal inicial.

O período experimental compreendeu as fases de crescimento e terminação. Os animais receberam dois tipos de rações de acordo com o sistema de arraçoamento por fases: ração de crescimento entre 63 a 106 dias de idade e ração de terminação entre 107 e 147 dias de idade. Em cada uma das fases as rações foram isoenergéticas, isocálcicas, isofosfóricas e isoaminoácidicas, formuladas para atender as exigências nutricionais dos animais, conforme apresentado na tabela I.

Uma amostra de FA foi enviada para o laboratório Labtec, Campinas/SP, para determinação das quantidades de gossipol. Os valores determinados foram de $385 \mathrm{ppm}$ de gossipol livre e de 863 ppm degossipol condensado. Para prevenir problemas causados pelo gossipol, foi utilizado sulfato de ferro na proporção de 1:1 (ferro:gossipol livre).

Foram avaliados os dados médios de consumo diário de ração, ganho diário de peso e conversão alimentar nos períodos de 63 a 106 dias de idade (período de 43 dias) e de 63 a 147 dias de idade (período de 84 dias), bem como as características qualitativas dos dejetos dos suínos, coletado semanalmente de cada baia.

Após a coleta cada amostra de dejetos foi acondicionada em saco plástico identificado por repetição e congelada. Ao término do período experimental, para cada repetição, foi feita uma amostra composta utilizandose as amostras coletadas semanalmente. A partir da amostra composta, aproximadamente $500 \mathrm{~g}$ do material foram levadas à estufa de ventilação forçada a $55^{\circ} \mathrm{C}$, por 72 horas, a fim de proceder a pré-secagem, para determinar a amostra seca ao ar. A seguir as amostras foram moídas em moinho tipo faca, com peneira de $1 \mathrm{~mm}$ e enviadas ao laboratório, junto com as amostras das dietas, para determinação dos teores de matéria seca, nitrogênio e fósforo, de acordo com a metodologia descrita Silva e Queiroz (2002).

Os resultados de desempenho e análise qualitativa dos dejetos foram analisados utilizado o seguinte modelo matemático:

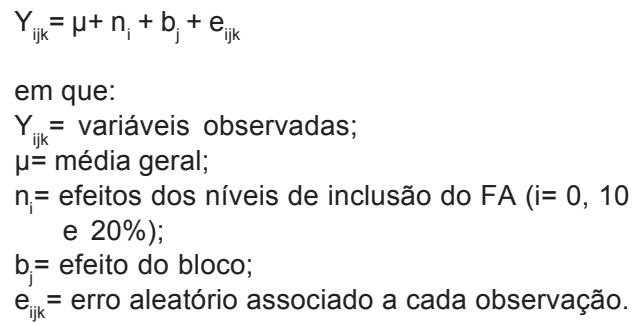

Em caso de significância foi realizada a regressão polinomial de acordo com o modelo estatístico:

$Y_{i j}=\mu+b 1\left(N_{i}-N\right)+b 2\left(N_{i}-N\right)+e_{i j}$,

em que:

$Y_{i j}=$ valor observado das variáveis estudadas, relativo a cada parcela j, recebendo o nível i de $\mathrm{FA}$;

$\mu=$ constante geral;

b1 = coeficiente de regressão linear do nível de FA sobre a variável $\mathrm{Y}$;

b2= coeficiente de regressão quadrático do nível de FA sobre a variável $Y$;

$N_{i}=$ níveis de $F A$ nas rações, sendo $i=0,10$ e $20 \%$; $\mathrm{N}=$ nível médio de $\mathrm{FA}$ nas rações;

$\mathrm{e}_{\mathrm{ij}}=$ erro aleatório associado a cada observação.

As análises estatísticas foram realizadas por meio do programa SAEG (2007).

Em cada um dos períodos (fase de crescimento e fases de crescimento e terminação) a viabilidade econômica foi avaliada por meio da estimativa do custo da ração por quilograma de suíno produzido, do índice de eficiência econômica e do índice do custo médio utilizando-se as fórmulas descritas por Bellaver et al. (1985) e Gomes et al. (1991). Entre os parâmetros econômicos, apenas o custo/kg de suíno produzido 
MELLO, LAURENTIZ, FILARDI, BERGAMASCHINE, OKUDA, LIMA E JUNQUEIRA

Tabela I. Composição percentual e níveis nutricionais das rações experimentais. (Percentual composition and nutritional levels of experimental diets).

\begin{tabular}{|c|c|c|c|c|c|c|}
\hline & \multicolumn{3}{|c|}{ Crescimento. Níveis de FA } & \multicolumn{3}{|c|}{ Terminação. Níveis de FA } \\
\hline & $0 \%$ & $10 \%$ & $20 \%$ & $0 \%$ & $10 \%$ & $20 \%$ \\
\hline \multicolumn{7}{|l|}{ Ingrediente } \\
\hline Milho & 71,45 & 70,71 & 66,90 & 76,80 & 73,20 & 69,52 \\
\hline Farelo de soja & 23,06 & 14,55 & 6,52 & 20,42 & 12,45 & 4,44 \\
\hline Farelo algodão & 0,00 & 10,00 & 20,00 & 0,00 & 10,00 & 20,00 \\
\hline Óleo de soja & 0,63 & 1,54 & 3,30 & 0,08 & 1,78 & 3,49 \\
\hline Calcário & 0,59 & 0,66 & 0,73 & 0,57 & 0,56 & 0,55 \\
\hline Fosfato bicálcico & 1,29 & 1,20 & 1,11 & 0,92 & 0,83 & 0,74 \\
\hline Sal comum & 0,36 & 0,37 & 0,37 & 0,34 & 0,34 & 0,35 \\
\hline L-Lisina HCL & 0,31 & 0,40 & 0,49 & 0,19 & 0,27 & 0,36 \\
\hline DL-Metionina & 0,06 & 0,05 & 0,04 & 0,01 & 0,01 & 0,01 \\
\hline SuplementoV/M ${ }^{1}$ & 0,50 & 0,50 & 0,50 & 0,50 & 0,50 & 0,50 \\
\hline Sulfato de ferro & 0,00 & 0,02 & 0,04 & 0,00 & 0,02 & 0,04 \\
\hline Inerte & 1,75 & 0,00 & 0,00 & 0,17 & 0,04 & 0,00 \\
\hline Total & 100,00 & 100,00 & 100,00 & 100,00 & 100,00 & 100,00 \\
\hline Custo/kg (US\$/kg) & 0,284 & 0,288 & 0,297 & 0,276 & 0,282 & 0,291 \\
\hline \multicolumn{7}{|l|}{ Níveis nutricionais } \\
\hline Energia metabolizável $(\mathrm{kcal} / \mathrm{kg})^{2}$ & 3200 & 3200 & 3200 & 3250 & 3250 & 3250 \\
\hline Cálcio $(\%)^{2}$ & 0,64 & 0,64 & 0,64 & 0,52 & 0,52 & 0,52 \\
\hline Fósforo total $(\%)^{3}$ & 0,57 & 0,61 & 0,60 & 0,55 & 0,50 & 0,53 \\
\hline Fósforo disponível $(\%)^{2}$ & 0,34 & 0,34 & 0,34 & 0,27 & 0,27 & 0,27 \\
\hline Proteína bruta $(\%)^{3}$ & 16,7 & 16,9 & 16,6 & 15,5 & 15,8 & 15,7 \\
\hline Fibra bruta $(\%)^{3}$ & 2,56 & 3,68 & 4,72 & 2,31 & 3,72 & 4,86 \\
\hline Lisina total $(\%)^{2}$ & 1,05 & 1,05 & 1,05 & 0,90 & 0,90 & 0,90 \\
\hline Lisina digestível $(\%)^{2}$ & 0,93 & 0,93 & 0,92 & 0,80 & 0,80 & 0,79 \\
\hline Metionina total $(\%)^{2}$ & 0,33 & 0,33 & 0,32 & 0,27 & 0,27 & 0,27 \\
\hline Metionina digestível $(\%)^{2}$ & 0,30 & 0,30 & 0,29 & 0,24 & 0,24 & 0,23 \\
\hline Treonina total $(\%)^{2}$ & 0,65 & 0,64 & 0,63 & 0,61 & 0,61 & 0,60 \\
\hline Treonina digestível $(\%)^{2}$ & 0,52 & 0,51 & 051 & 0,49 & 0,49 & 0,49 \\
\hline Triptofano total $(\%)^{2}$ & 0,23 & 0,22 & 0,22 & 0,22 & 0,21 & 0,21 \\
\hline Triptofano digestível $(\%)^{2}$ & 0,20 & 0,19 & 0,19 & 0,18 & 0,18 & 0,17 \\
\hline
\end{tabular}

'Suplemento vitamínico e mineral. Quantidade/kg de suplemento: Vit. A 2250000 UI, Vit. D3 450000 UI, Vit. E 4500 mg, Vit. K3 400 mg, Vit. B1 350 mg, Vit. B2 1000 mg, Vit. B6 350 mg, Vit. B12 4500 mcg, Niacina 7500 mg, Ác. pantotênico 4000 mg, Ác. fólico 100 mg, Biotina 25 mg, Colina 75000 mg, Promotor de crescimento 19000 mg, Antioxidante 25000 mg, Fe 80000 mg, Cu 12000 mg, Mn 70000 mg, Zn 100000 $\mathrm{mg}$, I $1000 \mathrm{mg}$, Se $120 \mathrm{mg}$.

${ }^{2}$ Valores calculados com base nos valores descritos por Rostagno et al. (2005). ${ }^{3}$ Valores analisados.

foi submetido à análise de variância, a qual seguiu o mesmo modelo utilizado para os parâmetros de desempenho. Os custos dos ingredientes (em dólares $/ \mathrm{kg}$ ) foram obtidos em março de 2010, na região noroeste do Estado de São Paulo.

\section{RESULTADOSEDISCUSSÃO}

Os parâmetros de desempenho avaliados na fase de crescimento e nas fases de crescimento e terminação (período total) não foram afetados $(\mathrm{p}>0,05)$ pelos níveis de

Archivos de zootecnia vol. 61, núm. 233, p. 58. 
FA adicionados às rações de crescimento $\mathrm{e}$ terminação (tabela II). Resultados semelhantes foram relatados por por Moreira et al. (2006), quando utilizaram 12\% de inclusão de FA na dieta inicial de suínos (15 a $30 \mathrm{~kg}$ ). No mesmo estudo, foi avaliado ainda o efeito da adição de sulfato ferroso como forma de evitar o efeito tóxico do gossipol, sendo que mesmo na ausência do sulfato ferroso o maior nível de inclusão do FA não comprometeu o desempenho dos animais, o que foi justicado pela baixa concentração do gossipol. No presente estudo o nível de gossipol livre no FA (385 ppm) também foi inferior ao limite máximo de 400 ppm, sugerido por Ezequiel (2002).

Paiano et al. (2006), avaliando quatro níveis de FA $(0,4,8,12$ e 16\%) não observaram efeitos dos níveis sobre o consumo diário de ração, porém observaram efeito quadrático sobre o ganho de peso diário e aumento linear na conversão alimentar, indicando que a piora na conversão alimentar decorreu do aumento nos teores de fibra. Em estudo anterior, avaliando níveis crescentes de FA $(0,5,10$ e $20 \%)$ na alimentação de suínos, Li et al. (2000) também observaram que o aumento no teor de fibra das rações comprometeu a conversão ali- mentar e o ganho de peso dos suínos tanto na fase de crescimento quanto na fase de terminação, indicando que o nível máximo de inclusão de FA é de $8 \%$.

No presente estudo, a inclusão de 10 e $20 \%$ de FA determinou aumento no teor de fibra de, respectivamente, $43,75 \%$ e $84,37 \%$, na ração de crescimento e de $61,04 \%$ e $110,39 \%$ na ração de terminação, isso em relação à ração isenta de $\mathrm{FA}$, porém os aumentos não afetaram ( $p>0,05)$ a conversão alimentar. A ausência de efeito dos níveis de FA sobre o consumo diário de ração, pode ter ocorrido em função das rações possuírem os mesmos níveis energéticos, o que também foi observado por Balogun et al. (1990), Li et al. (2000) e Paiano et al. (2006).

Entre os parâmetros qualitativos dos dejetos (tabela III), na fase de crescimento os níveis de FA afetaram apenas o teor de nitrogênio $(p<0,05)$ e fósforo $(p<0,01)$ e na fase de terminação o teor de matéria seca $(p<0,01)$. O teor de nitrogênio nos dejetos apresentou comportamento quadrático $\left(\% \mathrm{~N}=3,85+0,036 . \mathrm{FA}-0,0022 . \mathrm{FA}^{2}, \mathrm{R}^{2}=0,98\right)$ indicando redução a partir de $8,18 \%$ de FA (o máximo valor foi de 3,99\% de nitrogênio). Para o teor de fósforo nos dejetos foi observado efeito linear decrescente $(\% \mathrm{P}=1,5771$

Tabela II. Desempenho de suínos alimentados com diferentes níveis de farelo de algodão nas rações. (Performance of swine feeding with different cottonseed meals in the diets).

\begin{tabular}{lccccc}
\hline & $0 \% \mathrm{FA}$ & $10 \% \mathrm{FA}$ & $20 \% \mathrm{FA}$ & Valor de F CV (\%) \\
\hline Crescimento (63 a 106 dias ) & & & & & \\
$\quad$ Peso 106 dias (kg) & 55,06 & 55,89 & 54,77 & $0,188 \mathrm{NS}$ & 6,89 \\
$\quad$ Consumo diário de ração (g) & 1,817 & 1,852 & 1,809 & $0,213 \mathrm{NS}$ & 7,65 \\
Ganho diário de peso (g) & 0,775 & 0,781 & 0,768 & $0,121 \mathrm{NS}$ & 7,13 \\
Conversão alimentar & 2,34 & 2,37 & 2,33 & $0,297 \mathrm{NS}$ & 5,06 \\
& & & & & \\
Crescimento-terminação (63 a 147 dias) & & & & & \\
Peso 147 dias (kg) & 85,84 & 86,53 & 83,49 & $8,891 \mathrm{NS}$ & 5,59 \\
Consumo diário de ração (g) & 2,048 & 2,035 & 1,973 & $0,443 \mathrm{NS}$ & 8,42 \\
Ganho diário de peso (g) & 0,763 & 0,764 & 0,735 & $1,197 \mathrm{NS}$ & 5,72 \\
Conversão alimentar & 2,68 & 2,66 & 2,69 & $0,054 \mathrm{NS}$ & 6,12 \\
\hline
\end{tabular}

CV: coeficiente de variação. NS: no significativo. 
MELLO, LAURENTIZ, FILARDI, BERGAMASCHINE, OKUDA, LIMA E JUNQUEIRA

Tabela III. Características qualitativas de dejetos de suínos nas fases de crescimento e de terminação com base na matéria seca. (Qualitative characteristics of the of swine manure in the growth and finishing phase, with base in the dry matter).

\begin{tabular}{lccccc}
\hline & $0 \% \mathrm{FA}$ & $10 \% \mathrm{FA}$ & $20 \% \mathrm{FA}$ & Valor de F & CV (\%) \\
\hline Crescimento (63 a 106 dias de idade) & & & & & \\
$\quad$ Matéria seca (\%) & 30,24 & 30,92 & 31,99 & $1,59 \mathrm{NS}$ & 6,34 \\
$\quad$ Nitrogênio (\%) & 3,85 & 3,99 & 3,69 & $3,47^{* 1}$ & 5,86 \\
$\quad$ Fósforo (\%) & 1,57 & 1,42 & 1,25 & $11,17^{* * 2}$ & 9,32 \\
Terminação (107 a 147 dias de idade) & & & & & \\
$\quad$ Matéria seca (\%) & 29,99 & 32,44 & 33,66 & $6,52^{* * 3}$ & 6,06 \\
$\quad$ Nitrogênio (\%) & 4,05 & 4,16 & 4,18 & $2,09 \mathrm{NS}$ & 3,31 \\
$\quad$ Fósforo (\%) & 1,73 & 1,78 & 1,78 & $0,57 \mathrm{NS}$ & 6,53 \\
\hline
\end{tabular}

${ }^{1}$ Efeito quadrático: \% $N=3,85+0,036 \cdot X-0,0022 \cdot X^{2}\left(R^{2}=0,98 ; p<0,05\right)$.

${ }^{2}$ Efeito linear: $\% P=1,571-0,0156 . X\left(r^{2}=0,99 ; p<0,01\right)$.

${ }^{3}$ Efeito linear: \%MS= 30,478 + 0,0153.X $\left(r^{2}=0,76 ; p<0,01\right)$.

$\mathrm{CV}$ : coeficiente de variação. NS: no significativo.

-0,0156.FA, $\left.\mathrm{R}^{2}=0,98\right)$, com o aumento de inclusão do FA. Esses resultados indicam que a inclusão de FA causa redução dos teores de nitrogênio (a partir de 8,18\% de FA) e fósforo nos dejetos de suínos na fase de crescimento, porém esse comportamento não se repete para os dejetos analisados na fase de terminação.

$\mathrm{Na}$ fase de terminação o aumento no nível de FA determinou aumento linear no teor de matéria seca dos dejetos $(\% \mathrm{MS}=$ $\left.30,478+0,0153 \cdot \mathrm{FA}, \mathrm{R}^{2}=0,76\right)$, o que pode ter sido influenciado pelo aumento no teor de fibra, semelhante ao relatado por Decamp et al. (2001), que observaram que o aumento na inclusão de alimento fibroso na dieta de suínos pode determinar aumento no teor de matéria seca dos dejetos.

A inclusão de FA em substituição ao farelo de soja nas rações determinou a necessidade de adicionar diferentes níveis de óleo de soja e de L-lisina (tabela I) para que as mesmas permanecessem isonutritivas, o que acabou elevando o custo médio do quilograma das rações na fase de crescimento e no período total (tabela IV). $\mathrm{O}$ aumento no custo das rações contribuiu para o aumento no custo de produção para os tratamentos contendo FA, o que determinou índice de eficiência econômica e índice econômico inferiores.

Em relação à eficiência econômica da utilização de FA, Polinutri (2003) afirma que, em situações práticas, seu uso torna-se viável economicamente, quando seu preço representa $55 \%$ ou menos do preço do farelo de soja, o que não foi observado no presente estudo, onde o valor do FA representou $65 \%$ do preço do farelo de soja.

$\mathrm{Na}$ avaliação de um ingrediente alternativo na alimentação de suínos, muitas vezes a intenção não é necessariamente determinar se há vantagem nutricional, mas sim, determinar se o ingrediente suporta resultado compatível com a dieta referência (Lindemann et al., 2004). Dentro deste contexto, os resultados do presente estudo indicaram que animais alimentados com rações contendo FA apresentaram desempenho comparável àqueles alimentados com a dieta controle, entretanto, o custo do quilograma da ração aumentou, elevando assim o custo médio de produção do quilograma de suíno produzido em 2,51 e $5,34 \%$, respectivamente, para os animais alimentados com rações contendo 10 e $20 \%$ de inclusão do FA na fase de crescimento, e no período total o aumento foi de $1,53 \mathrm{e}$ 
FARELO DE ALGODÃO PARA SUÍNOS NAS FASES DE CRESCIMENTO E TERMINAÇÃO

Tabela IV. Avaliação econômica da utilização de farelo de algodão em rações para suínos na fase de crescimento e crescimento-terminação. (Economic evaluation of the use of cottonseed meal in swine diets at growing and growing-finishing phases).

\begin{tabular}{lccccc}
\hline & 0\% FA & 10\% FA & $20 \%$ FA & Valor de F CV (\%) \\
\hline Crescimento (63 a 106 dias de idade) & & & & & \\
$\quad$ Custo/kg de ração (US\$/kg de ração) & 0,284 & 0,288 & 0,297 & - & - \\
Custo/kg PV (US\$/kg de PV) & 0,666 & 0,682 & 0,701 & $1,06 \mathrm{NS}$ & 5,04 \\
$\quad$ Índice do custo médio & 100 & 102,51 & 105,34 & - & - \\
$\quad$ Índice de eficiência econômica & 100 & 97,55 & 94,93 & - & - \\
Crescimento-terminação (63 a 147 dias de idade) & & & & & - \\
$\quad$ Custo/kg de ração (US\$/kg de ração) & 0,276 & 0,282 & 0,291 & - & - \\
Custo/kg PV (US\$/kg de PV) & 0,739 & 0,751 & 0,784 & 1,88 NS & 6,11 \\
Índice do custo médio & 100 & 101,53 & 106,02 & - & - \\
Índice de eficiência econômica & 100 & 98,49 & 94,32 & - & - \\
\hline
\end{tabular}

CV: coeficiente de variação. NS: no significativo.

$6,02 \%$ para esses mesmos níveis de inclusão.

\section{CONCLUSÃO}

O FA pode ser utilizado em até $20 \%$ nas rações para suínos nas fases de crescimento e terminação sem afetar o desempenho, entretanto, é necessária a inclusão de Llisina, óleo de soja e sulfato de ferro nas

\section{BIBLIOGRAFIA}

Balogun, T.F., Aduku, A.O., Dim, N.I. and Olorunju, S.A.S. 1990. Undeorticated cottonseed meal as a substitute for soybean meal in diets for weaner and growing-finishing pigs. Anim Feed Sci Technol, 30: 193-201.

Bellaver, C., Fialho, E.T., Protas, J.F.S. e Gomes, P.C. 1985. Radícula de malte na alimentação de suínos em crescimento e terminação. Pesqui Agropecu Bras, 20: 969-974.

Chiba, L.I. 2001. Protein supplements. Swine Nutrition. $2^{\text {nd }}$ ed. Lewis, A.J. and L.L. Southern, Eds. CNS Publishing. Boca Roton. Flórida. pp. 803-837.

Decamp, S.A., Hill, B., Hankins, S.L., Bundy, D.C. and Powers, W.J. 2001. Effects of soybean hulls on pig performance, manure composition, and air quality. Purdue University. Swine Res Report, 13: 84-89. rações, o que determina aumento no custo/ $\mathrm{kg}$ de suíno produzido.

\section{AGRADECIMENTOS}

FAPESP - Fundação de Amparo a Pesquisa do Estado de São Paulo.

FEPE - Fazenda de Ensino Pesquisa e Extensão-FE/UNESP - Ilha Solteira.

Ezekiel, J.M.B. 2002. Farelo de algodão como fonte alternativa de proteína alternativa de origem animal. Simpósio sobre Ingredientes na Alimentação Animal. 2. Anais... Colégio Brasileiro de Nutrição Animal. Uberlândia. pp. 137-162.

Gomes, M.F.M., Barbosa, H.P., Fialho, E.T., Ferreira, A.S. e Lima, G.J.M.M. 1991. Análise econômica da utilização do triguilho para suínos. EMBRAPA. Centro Nacional de Pesquisa de Suínos e Aves. Comunicado Técnico, 179: 1-2.

Li, D.F., Xu, X.X. and Qiao, S.Y. 2000. Growth performance of growing-finishing pigs fed diets supplemented with Chinese cottonseed meal based on amino acids digestibilities. Asian Austral J Anim Sci, 13: 521-527.

Lindemann, M.D., Carter, S.D., Chiba, L.I., Dove, C.R., Lemieux, F.M. and Southern, L.L. 2004. A regional evaluation of chromium tripicolinate 


\section{MELLO, LAURENTIZ, FILARDI, BERGAMASCHINE, OKUDA, LIMA E JUNQUEIRA}

supplementation of diets fed to reproducing sows. J Anim Sci, 82: 2972-2977.

Marcato, S.M. and Lima, G.J.M.M. 2005. Efeito da restrição alimentar como redutor do poder poluente dos dejetos de suínos. Rev Bras Zootecn, 34: 855-863.

Moreira, I., Sartori, I.M., Painano, D., Martins, R.M. e Oliveira, G.C. de. 2006. Utilização do farelo de algodão, com ou sem adição de ferro, na alimentação de leitões na fase inicial. Rev Bras Zootecn, 35: 1077-1084.

NRC. 1998. National Research Council. Nutrient requirements of swine. $10^{\mathrm{a}} \mathrm{ed}$. National Academy of Science. Washington, D.C. 189 pp.

Paiano, D., Moreira, I., Silva, M.A.A., Sartori, I.M., Martins, R.M. e Vieira, F. 2006. Farelos de algodão com diferentes níveis de proteína na alimentação de suínos na fase inicial: digestibilidade e desempenho. Acta Sci Anim Sci, 28: 415-422.

Paiano, D., Moreira, I., Furlan, A.C., Silva, M.A.A., Hideo, J.H. e Patricio, V.M.I. 2003. Utilização do farelo de algodão para suínos em crescimento. XI Congresso Brasileiro de Veterinários Espe- cialistas em Suínos. Goiânia.

Polinutri. 2003. Utilização de farelo de algodão para suínos e aves. <http:// www.polinutri.com.br/ conteudo_dicas janeiro_03.htm> (01/03/2008).

Prawirodigdo, S., Batterham, E.S. and Andersen, L.M. 1997. Nitrogen retencion in pigs given diets containing cottonseed meal or soyabean meal. Anim Feed Sci Technol, 67: 205-211.

Rostagno, H.S., Albino, L.F.T., Donzele, J.L., Gomes, P.C., Oliveira, R.F. de, Lopes, D.C., Ferreira, A.S. e Barr, S.L.T. 2005. Composição de alimentos e exigências nutricionais. Tabelas Brasileiras para Aves e Suínos. UFV. Viçosa.

SAEG. 2007. Sistema de análises estatísticas e genéticas. Versão 9.1. Universidade Federal de Viçosa. UFV. Viçosa.

Silva, D.J. e Queiros, A.C. 2002. Análise de alimentos (métodos químicos e biológicos). UFV. Viçosa. $235 \mathrm{pp}$.

Tanksley, T.D. 1990. Cottonseed meal. In: Thacker P.A. and Kirkwood R.N. (Eds.). Nontraditional feed sources for use in swine production. Butterworth Publishers. Stoneham, Massachusetts. pp. 139-151.

Archivos de zootecnia vol. 61, núm. 233, p. 62. 